\title{
O Projeto EMAI na Percepção de Professores que Ensinam Matemática nos Anos Iniciais do Ensino Fundamental: problematizando a questão da autonomia docente
}

\author{
The EMAI Project in the Perception of Teachers who Teach Mathematics \\ in the Early Years of Elementary School: problematizing the question of \\ teacher autonomy
}

Dugusta Teresa Barbosa Severino'

Denata Cristina Geromel Meneghetti ${ }^{2}$

\begin{abstract}
'Universidade Estadual Paulista (UNESP), Faculdade de Ciências, Programa de Pós-Graduação em Educação para a Ciência, Bauru, SP, Brasil. Autora correspondente: atb.severino@unesp.br

${ }^{2}$ Universidade de São Paulo (USP), Instituto de Ciências Matemáticas e de Computação (ICMC), São Carlos, SP, Brasil.
\end{abstract}

Resumo: Este artigo tem como objetivo evidenciar as percepções dos professores que ensinam matemática nos anos iniciais do Ensino Fundamental sobre a utilização do material do projeto Educação Matemática nos Anos Iniciais - EMAI - quanto à autonomia docente no planejamento, execução e avaliação do plano de ensino de matemática e sua execução em aula. Trata-se de uma investigação qualitativa, realizada por meio de pesquisa de campo e entrevistas semiestruturadas. Como resultado foi possível evidenciar que os docentes têm uma percepção limitada de autonomia e da interferência dela na construção da identidade docente condicionada à execução do trabalho, obedecendo a uma racionalização no cumprimento das regras e técnicas, sem a devida reflexão. Eles afirmaram gostar do material, mas ter dificuldades e insegurança em trabalhar com a matemática e atribuem isso às lacunas advindas da falta de suporte teórico, metodológico e prático. Tais apontamentos indicam a necessidade de repensar a formação docente de professores com esse tipo de atuação.

Palavras-chave: Ensino de matemática; Ensino fundamental; Autonomia docente; Identidade docente; Formação de professores; Projeto EMAI.

Abstract: This article aims to show the perceptions of teachers who teach mathematics in the early years of elementary school about the use of the Mathematics Education in the Early Years- EMAI - project material, regarding teacher autonomy in the planning, execution and evaluation of the mathematics teaching plan and its execution in class. This is a qualitative investigation, carried out through field research and semi-structured interviews. As a result, it was possible to show that the teachers have a limited perception of autonomy and its interference in the construction of the teaching identity conditioned to the execution of the work, obeying a rationalization in the fulfillment of the rules and techniques, without due reflection. Teachers said they like the material but experience difficulties and insecurity working with mathematics, and attribute that to the gaps arising from the lack of theoretical, methodological and practical support. Such notes indicate the need to rethink teacher training for teachers with this type of performance.

Keywords: Mathematics teaching; Elementary school; Teaching identity; Teacher autonomy; Teacher training; EMAI Project.

Recebido em: 02/04/2020

Aprovado em: 10/02/2021 


\section{Introdução}

Este artigo se refere a uma pesquisa de dissertação de mestrado da primeira autora com orientação da segunda e teve como objetivo evidenciar as percepções dos professores que ensinam matemática nos anos iniciais do Ensino Fundamental sobre a utilização do material do Projeto EMAI (Educação Matemática nos Anos Iniciais) quanto à limitação da autonomia docente no planejamento, execução e avaliação do próprio plano de ensino, bem como nas atividades cotidianas em sala de aula para o ensino da matemática.

De acordo com Contreras (2002), a autonomia docente é entendida como uma construção pessoal que demanda o trabalho em equipe, a emancipação intelectual e a libertação das amarras do sistema ideológico, por meio do questionamento das imposições sobre concepções de ensino e aprendizagem. Nesse sentido, a evolução cotidiana do professor na construção de sua autonomia e identidade profissional está atrelada a uma busca contínua por formação que lhe dê suporte teórico e metodológico para a tomada de consciência da importância de sua atuação crítica e transformadora.

Seguindo tal objetivo, foi utilizada a pesquisa qualitativa como metodologia estruturante, realizada por meio de pesquisa de campo, através de entrevistas semiestruturadas com um grupo de professores que utilizaram o material desde a sua implantação. As respostas foram analisadas e discutidas à luz do referencial teórico que alicerça a pesquisa, o qual é de fundamental importância para o entendimento da realidade educacional como resultado de um processo histórico complexo, que coloca o professor na posição de simples executor das demandas do sistema.

O projeto EMAI foi idealizado pela Secretaria de Estado da Educação de São Paulo, em 2012, e efetivamente implantado na rede estadual em 2013. O projeto apresenta em cada unidade as chamadas Expectativas de Aprendizagem, ou seja, as metas definidas para a aprendizagem dos alunos para cada eixo, distribuídas em livros semestrais: números e operações; grandezas e medidas; espaço e forma; e tratamento da informação (SÃO PAULO, 2013).

O desenvolvimento das atividades está descrito no material do professor para que ele componha seu plano de ensino e suas aulas de matemática em três momentos: conversa inicial, problematização e observação/Intervenção, explicitando os encaminhamentos de cada atividade, as questões que o professor deve fazer para conduzir o diálogo, aquilo que deve observar na execução e como deve intervir; a fim de que se possa, ao final de cada eixo, atingir as expectativas determinadas.

Dessa maneira, a inquietação de investigar nos levou a buscar respostas sobre essa percepção do professor quanto à limitação do trabalho em sala de aula, direcionada ao cumprimento das apostilas e materiais didáticos, evidenciando de que maneira esse professor percebeu sua atuação, limitada ou não, condicionada ou não ao material didático por meio das respostas (falas) decorrentes das entrevistas semiestruturadas.

Diante desse cenário, estabelecemos as seguintes questões de investigação: como os professores entrevistados entendem sua autonomia docente na utilização desse material didático? Qual a contribuição desse uso no que concerne à construção de sua identidade docente?

Esses questionamentos buscam elucidar, por meio da análise e discussão, as maneiras pelas quais a autonomia docente é cerceada pela imposição do material 
didático que determina os caminhos que o professor deve seguir para superar o fracasso na qualidade do ensino público, em especial no que se refere à matemática.

Desse modo, entendemos que esta pesquisa poderá trazer contribuições importantes para as discussões sobre o ensino e a aprendizagem de matemática nos anos iniciais do Ensino Fundamental e, mais especificamente, à prática docente de professores que lecionam nesse nível de ensino.

Para tanto, este texto está organizado em três seções: na primeira, faremos a explanação dos pressupostos teóricos que fundamentaram a pesquisa; na segunda, serão apresentados os procedimentos metodológicos, entrevistas e discussões sobre as respostas; e, para finalizar, faremos a apresentação das considerações finais, retomando os pontos principais de todo o texto.

\section{Pressupostos teóricos}

A estrutura teórica do presente texto está alicerçada em três pontos de reflexão acerca do trabalho com o material EMAl: a formação de professores; o processo de construção da identidade docente e a autonomia docente como parte essencial desse processo de construção. Nesse caminho, buscamos compreender até que ponto os professores que utilizam o material sentem e/ou percebem a influência das imposições do sistema sobre sua autonomia e, consequentemente, como essa ação suscetibiliza à construção de sua identidade profissional que se faz no cotidiano e na união entre a teoria estruturante e uma prática determinada para cumprir as exigências e os interesses que moldam a sociedade.

$\mathrm{Na}$ literatura encontramos teóricos que vão à contramão do sentido específico aqui discutido: o projeto EMAI como limitador da autonomia docente e elemento de coação ideológica para discutirem a utilização do material do Projeto e suas vantagens. Dessa maneira, para Silva (2015), por exemplo, a implantação do projeto EMAl trouxe benefícios aos professores no sentido de lhes proporcionar uma formação continuada para o entendimento e aplicação do currículo nele prescrito. O autor também discorre sobre as formas de avaliação para atender às expectativas de ensino e aprendizagem ao longo do processo de aplicação do material.

Por meio da pesquisa realizada foram feitas reflexões acerca da implantação e do uso do material didático como limitadores da autonomia docente. Entendemos, pois, que a educação escolar é parte essencial e potente da construção de uma resistência politizada pelo acesso aos objetos de conhecimento que permitem a apropriação das ferramentas de compreensão da realidade e de luta pela organização da classe trabalhadora enquanto classe transformadora (GRAMSCI, 1968).

Nesse sentido, Saviani (2005) afirma que a educação escolar pública que se propõe ao desafio de instrumentalizar a classe popular expropriada dos direitos e do acesso ao conhecimento, necessita ter em seu bojo professores conscientes de seu papel fundamental na organização do saber científico transformado em saber escolar, de modo a instrumentalizar os estudantes e oportunizar a apropriação do conhecimento sistematizado. Para tanto, utiliza todas as ferramentas necessárias para encaminhar os processos de aprendizagem e os avanços, a partir do conhecimento sincrético e desorganizado, para um conhecimento sintético, crítico, consciente e organizado.

Enfatizamos uma formação sólida que proporcione ao professor a oportunidade de resistir, escolher, trabalhar dentro de uma práxis educativa consciente de sua ação 
política enquanto intelectual organizador da cultura, como afirma Gramsci (1982). Entretanto, essa práxis só é possível pela relação latente da consciência com a realidade, desenvolvida por meio de um processo de conscientização que transforma e é transformado no movimento histórico, político e filosófico, alicerçado na organização coletiva, no aprofundamento teórico e na ação como princípios de transformação (LUKÁCS, 2003).

O entendimento de autonomia, nesta pesquisa, alicerçado nos estudos de Freire (1996), Contreras (2002) e Saviani (2005), destarte, sustenta-se na práxis educativa consciente das determinações e organizada na resistência construída sobre alicerces teóricos sólidos, no domínio conceitual e metodológico que permitam o desvencilhar das imposições do sistema e a utilização dos materiais didáticos como mais um instrumento de acesso ao conhecimento sistematizado e não como rédeas que determinam as ações e o pensamento do professor e dos alunos.

No que tange a questão da formação docente dos anos iniciais, assistimos a um constante processo histórico de desvalorização da carreira pelos governos e suas políticas públicas de um modo geral e, ao aligeirar os cursos de formação de professores, especialmente o de Pedagogia, que podem ser concluídos em curtos espaços de tempo e com uma grade curricular limitada, acabam reduzindo também a qualidade da formação desse professor do ponto de vista procedimental e, sobretudo, conceitual. A disciplina de matemática envolve diversos conceitos e habilidades os quais necessitam ser devidamente aprendidos, aprofundados e focalizados pelo professor, pois, de outro modo, poderá tornar a aula um simples completar de atividades sem aprofundamento teórico.

Para Saviani (2008), esse processo histórico e político da formação do pedagogo comprova a concepção que subordina a educação à lógica do mercado, sendo a educação escolar o reflexo da produtividade social, ajustada ao mercado de trabalho e à sociedade em que vivemos.

\footnotetext{
Nessas circunstâncias, a questão educativa é reduzida dominantemente à sua dimensão técnica, afastando-se o seu caráter de arte e secundarizando, também, as exigências de embasamento científico. Daí a pretensão de formar os especialistas em educação por meio de algumas poucas regras compendiadas externamente e transmitidas mecanicamente, articuladas com o treinamento para a sua aplicação no âmbito do funcionamento das escolas (SAVIANI, 2008, p. 51).
}

A inserção desse professor na escola, formado e treinado nos moldes do sistema mercadológico, pressupõe a garantia da continuidade dos parâmetros estabelecidos pela organização da educação escolar e pela racionalidade técnica desse professor, que trabalhará os currículos e programas de modo eficiente e produtivo, como um ciclo em favor da lógica do mercado de trabalho. Reconhecemos a validade das afirmações de Martins (2010) ao enfatizar que a formação de professores, tanto inicial quanto continuada, vem ao longo da história em um constante aligeirar-se proporcional ao esvaziamento do que deveria ser essencial em seu bojo: a apropriação do patrimônio intelectual da humanidade.

Tem-se o peso da balança pendido para o campo da prática em detrimento da teoria, entretanto, do ponto de vista da relação dialética entre teoria e prática, como afirma Freire (1996), deveria haver um equilíbrio entre elas, entre conteúdo e forma, 
sendo que um não se constrói sem o outro, mas a partir do outro na formação do sujeito e na construção de sua autonomia.

Para Monteiro (2006, p. 117), as "[...] concepções mais recentes das pesquisas em educação apontam que professor autônomo é aquele [...] capaz de elaborar e gerir um currículo". Entretanto, consideramos que ser autônomo vai muito além do currículo escolar, pois está imbricado em uma teia de relações pessoais e conceituais que permeiam todo o processo de construção do ser professor, alicerçada no domínio dos aspectos históricos, teóricos, práticos, políticos e filosóficos que cercam o indivíduo que, ao se apropriar dos elementos, humaniza-se e vai se modificando durante toda a sua trajetória de estudos, trabalhos e reflexões, que a partir daí poderá ser chamada de crítica pela possibilidade de compreender as relações sociais de poder e buscar, pelo conhecimento que é seu, como sua segunda natureza, a transformação da sociedade (SAVIANI, 2003).

Nesse sentido, a teoria advinda da formação inicial e continuada, aliada à prática pedagógica construída no processo de desenvolvimento do ser professor, constituemse elementos essenciais na construção da identidade autônoma. Sobre essa construção através da prática, Freire (1996, p. 24) propõe a seguinte analogia: "A prática de velejar coloca a necessidade de saberes fundantes como o do domínio do barco, das partes que o compõem e da função de cada uma delas, como o conhecimento dos ventos, de sua força, de sua direção [...]". Portanto, é preciso conhecimento teórico para suprir a prática e a prática para confirmar a teoria, um movimento contínuo de dependência dialética.

Para Cunha (2006, p. 258), a docência é uma ação humana, histórica e cultural e, portanto, "[...] está imbricada numa teia de significados que constituem os sujeitos". Os professores precisam ser sujeitos ativos no exercício da docência e ter uma relação de respeito e troca com o outro que, por serem críticos e conscientes de sua atuação política, são conhecedores de suas capacidades e dos meios para as apropriações e ampliações dos conhecimentos historicamente acumulados, ou seja, os professores precisam ser educandos em constante processo de formação e construção de sua identidade (FREIRE, 2016).

Esse conhecimento historicamente acumulado que defendemos aqui não evidencia apenas a importância do trabalho com os conteúdos já determinados pelos currículos escolares em sala de aula, mas enfatiza também a necessidade de que as pesquisas mais atuais, desenvolvidas nos âmbitos científico e tecnológico, cheguem ao estudante da escola pública. A tendência de atribuir ao ensino público um currículo mínimo é uma das formas de dar a esses alunos a ínfima ideia de educação de qualidade. Os professores, como intelectuais, precisam saber transformar em conteúdos escolares, o que foi e o que é produzido pela ciência, organizando seus estudantes para o processo de apropriação desses conteúdos. Falar em conhecimento historicamente acumulado é falar dos bens culturais da sociedade no processo de humanização, apropriação e produção do saber, que é desenvolvido no decorrer de toda a história humana e destinado sumariamente à elite. Parafraseando Saviani (2005, p. 55), "[...] dominar o que os dominantes dominam é condição de libertação".

A partir disso, é possível, tal como preconiza Contreras (2002), conceber a ideia de identidade autônoma como um processo em constante construção e reconstrução, o qual, além de reconhecer as determinações impostas pelo sistema, também atua no 
sentido da resistência política que vai sendo transformada durante todo o processo de busca pelo conhecimento e na aplicação prática.

Além disso, sua atuação se alicerça na reflexão sobre o processo transformador da educação escolar, em que todos os envolvidos são modificados, de modo qualitativo e quantitativo pela apropriação do conhecimento historicamente acumulado pela humanidade, que se desenvolve a cada dia nos avanços científicos e tecnológicos e precisam fazer parte do ensino público de qualidade.

Para Heller (1992 apud MONTEIRO, 2006, p. 129), o que existe é a chamada "identidade do mito", evidenciada pela inserção automática do indivíduo, professores e alunos, na realidade, na qual o sujeito acaba sendo moldado de maneira a executar e reproduzir ações prontas, sem criatividade e criticidade. Uma identidade docente que, muitas vezes, se supõe autônoma, mas, na maioria das vezes, está condicionada a uma autonomia relativa. A autonomia, como já explicitado anteriormente, é um conceito complexo que envolve inúmeros fatores, em especial o reconhecimento das interferências do sistema e a tomada de consciência da ação educativa como ponto fundamental na transformação social.

Para Saviani $(2002,2005)$, os professores têm papel fundamental no acesso do aluno aos objetos de conhecimento, na qualidade teórica e metodológica que dá suporte às suas aulas e no modo como planeja cada etapa para que todos os envolvidos se sintam parte do processo educativo e, por isso, precisam se perceber como indivíduos capazes de mudar a situação do ensino, como filósofos que pensam os problemas da educação e educadores na totalidade do ensino.

A formação do docente é parte fundamental na construção de uma autonomia consciente e na constituição dos saberes específicos para a prática, por isso a necessidade de repensar aspectos referentes à formação inicial e continuada, a qual precisa suprir as necessidades de uma formação limitada em termos teóricos e práticos, em especial no que se refere à matemática. São essas as partes fundamentais na construção de uma autonomia que seja real, alicerçada na ação consciente do professor frente ao desafio de lecionar. A formação é a mola propulsora da compreensão que se tem sobre a autonomia e o ato educativo.

No que segue, serão delineados os caminhos percorridos para a construção metodológica desta pesquisa.

\section{Pressupostos metodológicos da pesquisa}

Esta investigação tem uma abordagem qualitativa e optamos pela pesquisa de campo e entrevistas semiestruturadas com professores que utilizaram o material EMAI desde sua implantação para permitir a vivência da pesquisadora com todas as nuances do cotidiano escolar, a possibilidade de uma análise mais clara e precisa dos diálogos e da complexa rede de relações que envolvem contexto e indivíduos (BOGDAN; BIKLEN, 1994).

A pesquisa ocorreu em uma escola estadual do interior do Estado de São Paulo que atende alunos do primeiro ao quinto ano do Ensino Fundamental e utilizaram o material do projeto EMAI, desde o ano de 2013. Nessa escola, os professores receberam o curso de formação oferecido pela própria Coordenadora Pedagógica (CP) da unidade, no qual discutiram a respeito da aplicação do material em sala de aula e atividades propostas a serem desenvolvidas de acordo com as recomendações do livro 
do professor. Essa escola foi escolhida por ser o local de trabalho da primeira autora há mais de dez anos e, portanto, pela facilidade de acesso à direção da unidade e aos professores; além da familiaridade com o ambiente de trabalho e os participantes da pesquisa.

Inicialmente, a proposta da pesquisa foi apresentada a 12 professores e à $C P$, em uma das reuniões de trabalho pedagógico. Porém, apenas três professoras: Eva, Joana e Rita; e a CP: Maria; mencionadas aqui com nomes fictícios, aceitaram participar. As entrevistadas se assemelharam em três importantes aspectos: (i) estar na mesma unidade desde a efetiva implantação do projeto em 2013; (ii) ter participado do curso de formação durante todo o ano de 2014 e estar participando em 2015; (iii) ter mais de dez anos de experiência como docente.

A entrevista semiestruturada foi composta por 18 questões abertas que versavam sobre: a formação de cada uma, o trabalho com o material e as percepções a respeito da própria autonomia frente à utilização do material. Optamos pela produção de dados através de entrevistas semiestruturadas, pela liberdade de opiniões e pela interação entre pesquisador e sujeito da pesquisa (LUDKE; ANDRÉ, 1986).

Esse tipo de entrevista pode ser evidenciado como uma forma de diálogo que traz a possibilidade de se colocar na posição do outro, no reconhecimento da própria incompletude diante do mundo e das coisas. Segundo Freire (1996), a vivência dessa abertura ao outro, tomando a prática como objeto da reflexão crítica, deve fazer parte da aventura docente, por sua razão ética, fundamento político, referência pedagógica e, ainda, pela beleza que há no diálogo.

Assim, na apresentação de trechos das entrevistas, buscamos evidências que demonstrassem o entendimento referente ao próprio trabalho; sobre a questão da autonomia docente diante das imposições cotidianas, do ensino dos conteúdos matemáticos por meio do projeto EMAI e sobre as variáveis que influenciam na construção da identidade docente.

Após a transcrição das entrevistas iniciamos o processo de análise das respostas, visando perceber a compreensão de cada uma sobre a questão da autonomia docente frente ao trabalho com o material EMAl, além de buscar respostas à nossa hipótese inicial de que tal material limita a atuação do professor em sala de aula pela imposição das sequências de atividades a serem desenvolvidas e da condução e avaliação da aula, designando-lhe o papel de executor de tarefas determinadas e, consequentemente, sua autonomia no planejamento, elaboração, aplicação e avaliação das próprias aulas.

No que segue, faremos a discussão dos principais dados e resultados advindos das entrevistas e, por fim, traçaremos as considerações finais.

\section{Análise das entrevistas}

No quadro 1 apresentamos informações sobre as participantes da entrevista, no que se refere à formação, tempo de atuação e ano em que estava lecionando na ocasião da realização das entrevistas. 
Quadro 1 - Informações gerais das entrevistadas

\begin{tabular}{|l|l|l|c|l|}
\hline Professoras & \multicolumn{1}{|c|}{ Formação inicial } & \multicolumn{1}{|c|}{ Pós-graduação } & $\begin{array}{c}\text { Tempo de } \\
\text { atuação (anos) }\end{array}$ & $\begin{array}{l}\text { Ano escolar em que } \\
\text { atua (em 2015) }\end{array}$ \\
\hline Eva & Letras e Pedagogia & $\begin{array}{l}\text { Psicopedagogia; Ética, } \\
\text { valores e cidadania; Gestão } \\
\text { escolar }\end{array}$ & 13 & $5^{\circ}$ ano \\
\hline Joana & Psicologia e Pedagogia & Formação de Psicólogo & 26 & $2^{\circ}$ ano \\
\hline Rita & Pedagogia & Psicopedagogia; Educação & 26 & $2^{\circ}$ ano \\
\hline Maria & $\begin{array}{l}\text { Curso de formação para pro- } \\
\text { fessores dos anos iniciais }\end{array}$ & Alfabetização e Letramento & 24 & $\begin{array}{l}\text { Atua há um ano e meio } \\
\text { como CP }\end{array}$ \\
\hline
\end{tabular}

Fonte: elaborado pelas autoras.

É possível perceber que todas as professoras entrevistadas têm um tempo considerável de experiência (mais de dez anos) nos anos iniciais do Ensino Fundamental. No entanto, elas enfatizaram que, apesar disso, há ainda necessidade de intenso estudo antes das aulas de matemática, pois identificaram a disciplina sendo difícil de aprender e ensinar devido à limitada formação inicial e continuada que tiveram para o trabalho com essa disciplina. Sobre isso, apresentamos o exemplo: "Falta-me formação para fazer os alunos entenderem determinados conceitos e estratégias..." [Profa. Rita].

É exatamente essa falta de formação específica, mesmo em relação às formações continuadas que já participaram durante a carreira docente, que, segundo elas, desencadeou insegurança para o trabalho com a matemática, por isso, apontaram a necessidade de terem um suporte material, como o projeto EMAl e os livros didáticos, para dar início e sequência às aulas e, assim, seguir o currículo.

[...] posso dizer que minha formação nessa disciplina é muito precária. Não tive disciplinas como: física e química. A matemática foi muito precária, focando mais em metodologias e não em conteúdos e conceitos matemáticos. [Profa. Eva].

Minha formação inicial deixou muitas lacunas. Embasada nos métodos tradicionais, não me preparou adequadamente para a atuação em sala de aula. [Profa. Joana].

Todas afirmaram que tiveram uma formação inicial precária em conteúdos e conceitos matemáticos, acarretando dificuldades e insegurança no planejamento, execução, retomada e avaliação das atividades diárias no ensino de matemática. $O$ termo que mais apareceu nas respostas foi lacuna, tanto teórica quanto prática, para trabalhar com a matemática. Por esse motivo, é possível entender a necessidade que as professoras sentiam de buscar auxílio em materiais didáticos.

Eu penso assim: o EMAl é um material que foi criado para facilitar o trabalho e para criar um parâmetro mesmo e, nesse sentido, eu penso que ele veio pra ajudar... [Profa. Joana].

Nesse sentido, os dados coletados dão indícios à afirmação de que a formação do docente é parte fundamental na construção de uma autonomia consciente e na constituição dos saberes específicos para a prática. Para Monteiro (2006), em sua tese de doutorado, no contexto da formação de professores, a autonomia vivenciada pelas professoras é mascarada pela imposição de um material pronto, com o currículo previamente estabelecido e a "receita" para o fazer pedagógico e não a gerência dele. A análise do autor desta tese se assemelha à nossa, pois também destacamos a interferência de um material didático específico na autonomia docente. 
Assim, o processo de construção da identidade docente se alicerça em uma autonomia que classificamos aqui como relativa, limitada à execução de sequências didáticas previamente determinadas, ao mesmo tempo em que se estrutura em práticas pedagógicas, experiências e relações que não permitem uma atuação consciente frente às imposições do sistema e ao entendimento sobre o processo de formação do indivíduo.

Quando questionadas sobre sua compreensão a respeito de seu exercício docente frente ao projeto EMAI, apresentaram respostas limitadas, atreladas apenas à regularidade na execução das atividades para atender ao currículo:

Eu penso assim: o EMAI é um material que foi criado para facilitar o trabalho. Inclusive eu penso que quando um aluno nosso, por exemplo, vai para outra escola e ele está trabalhando aqui e ele vai pra lá, tem certa regularidade no que está se trabalhando no currículo... [Profa. Joana].

É possível perceber que as professoras não identificaram a importância da participação do professor na construção do currículo, aceitaram com passividade o fato de terem que seguir um currículo pronto, não vendo isso como parte das especificidades da prática educativa autônoma (CONTRERAS, 2002). Muitas vezes, elas recorriam às falhas do ensino tradicional para justificar o sentimento de salvação na utilização do projeto EMAI.

Eu percebo o seguinte: o ensino tradicional era através de muita repetição e inúmeras folhas, o ensino era fragmentado. Mas hoje há a necessidade de você ampliar o ensino e não limitar, e o EMAl, as atividades que o complementam e o estudo do professor, ajudam no ensino e na aprendizagem da Matemática. [CP Maria].

Isso mostra uma limitada percepção das imposições ideológicas que são mascaradas por um discurso de liberdade e valorização do professor pelo material didático, como se o uso do material não fosse também um limitador do ensino e da aprendizagem. Acabam tirando o foco do ensino tradicional de repetição e inúmeras folhas e não percebem que a imposição de um material didático também se traduz no controle da técnica tanto dos professores quanto dos alunos. Para Pêcheux (1982 apud GREGOLIN, 2006), há uma profunda relação entre a ideologia e o inconsciente, pois ambos operam ocultando sua existência e produzindo verdades subjetivas que organizam uma unidade de pensamento, uma aceitação passiva.

Há uma crença fortemente enraizada de que existe autonomia no simples fato de se ter em mãos um material que unifica o currículo e apresenta determinadas atividades que remetem a um conceito, mas o deixa pouco explorado.

Eu gosto da forma como ele encadeia as atividades, ele trabalha os quatro eixos, eu acho isso muito importante, principalmente na questão da geometria, porque nós sempre deixamos a geometria para o final e ela não é trabalhada ou é trabalhada de uma forma extremamente superficial... [Profa. Joana].

Seguindo nessa direção, tem-se a impressão de que o projeto EMAl veio para salvar o ensino da matemática ou garantir que se ensinem determinados conteúdos que antes eram deixados de lado. Reconhecemos a importância desse ponto de vista, entretanto, evidenciamos que a utilização do material por si só não garante a profundidade do ensino dos conceitos, pois mesmo que o professor estude antecipadamente as atividades propostas, as dificuldades conceituais ainda persistirão e a aprendizagem será tão fantasiosa quanto o ensino, pois a prática do professor 
se sustenta no material e não na segurança de seu próprio conhecimento teórico, conceitual. Para complementar esse apoio no material, apresentamos os trechos que seguem:

[...] o EMAI nas minhas aulas é trabalhado como um todo, então eu utilizo todos os aspectos e as indicações de procedimentos e atividades. [Profa. Eva].

[...] utilizo o EMAl diariamente e continuamente, seguindo todas as atividades, conforme as indicações do programa, tentando seguir todas as etapas, adaptando apenas de acordo com o tempo. [Profa. Rita].

O EMAI se tornou o principal material para a condução das aulas de matemática, um facilitador do processo de preparação das aulas, visto que é preciso apenas cumprir as determinações para a execução correta das atividades, bastando que o professor siga essas determinações e adapte cada sequência de acordo com o tempo, já que precisa dar cabo dos livros no decorrer do ano letivo. Para que o material seja trabalhado como tal, a CP afirma que auxilia os professores, durante os chamados cursos de formação que ocorrem na própria unidade escolar, no processo de entendimento das atividades mais difíceis.

Nós temos o grupo de quinta-feira destinado ao estudo do EMAl, então, proponho aos professores que estudem as sequências de atividades para ver quais atividades são mais difíceis para o ensino e a aprendizagem e, assim, trabalhamos durante o período... [CP Maria].

Não há, portanto, um necessário processo reflexivo acerca da estrutura do material, das imposições ideológicas que o sustentam e da percepção ou não sobre a limitação da autonomia docente. A ênfase está na atividade em si, no modo como ela será aplicada na íntegra. Entretanto, mesmo enfatizando que o material traz certa segurança, as professoras foram categóricas em afirmar que sentem dificuldade, por uma formação precária para o trabalho com a matemática, em fazer a sistematização do conceito e das estratégias de resolução da atividade proposta.

A sistematização do conteúdo é simplesmente passada no EMAI. É preciso que as etapas do ensino sejam respeitadas, preciso de operacionalização e sistematização para facilitar as estratégias de resolução de problemas. Preciso que essa sistematização final esteja clara no material, pois eu não sei fazer sozinha. [Profa. Rita].

Algumas coisas pragente trabalhar, ter um trabalho sistemático, vocêtem que fazer uma complementação. Falta-me segurança, mas eu preciso complementar, algo que não sei se está certo... [Profa. Eva].

A veemência das respostas, como no trecho "eu não sei fazer sozinha", justifica a necessidade e o apego ao material didático, confirmando que uma formação limitada em termos conceituais e procedimentais impede o exercício da autonomia docente de forma plena, tornando-a relativa, condicionada a determinações externas. Destacamos, mesmo não sendo o foco do artigo, que a 'cobrança' no cumprimento do material, como constatamos nas falas apresentadas, acaba gerando nos professores uma sobrecarga emocional que leva à insatisfação com o próprio trabalho e à conclusão de que nunca conseguirá fazer sozinho e, se fizer algo, não saberá se está certo, pois não tem segurança para isso.

Nesse sentido, é possível perceber que a fala da CP Maria mostra certo descontentamento com o projeto EMAI que, como outros programas do governo, obrigam as escolas e os professores a trabalharem de acordo com as proposições sem oferecer formação adequada. 
Discordo do modo como foi implantando, pois a gente sabe que esses programas vêm de 'cima para baixo' e o professor é obrigado a trabalhar sem um curso de formação adequado que o ajude a entender os conteúdos e os procedimentos... [CP Maria].

De forma geral, foi possível observar, através da análise das entrevistas, que havia um apreço pelo material didático. Esse fato pode ser elucidado pelos trechos que seguem, nos quais se apresentam as vantagens da implantação do projeto EMAI. É preciso esclarecer que esta foi a única fala, dentre as entrevistadas, que apontou problemas decorrentes da implantação desse material.

Eu penso que o diferencial dele é que está bem mais adequado ao nosso currículo. E está ali, nas mãos dos alunos. Muitas vezes, eu escolhia um livro didático e não vinha o livro que eu queria trabalhar, às vezes vinha um livro que não estava de acordo com o currículo. [Profa. Joana].

O EMAl veio, depois de muitos anos perdidos, para colocar, de forma clara, como trabalhar com a Matemática. A gente não aprendeu a trabalhar a Matemática, não temos formação para isso. Então o objetivo é colocar um pouco de ordem no trabalho do professor. [Profa. Rita].

A fala da professora Rita demonstrou claramente que a falha em sua formação referente à aprendizagem de conteúdos de matemática interferiu significativamente na segurança para preparar e conduzir suas próprias atividades, resultando no excesso de confiança depositada no material.

Reafirmaram a todo o momento que o EMAI é mais adequado que o livro didático por unificar a proposta e o currículo, para que todos os professores da rede "falem a mesma língua". Ainda foram categóricas em afirmar que, para que funcione como um catalisador de conhecimentos, o material precisa ser trabalhado em todas as suas dimensões, ou seja, seguindo exatamente os caminhos que ele aponta em cada atividade.

As dúvidas intensificam a insegurança das professoras e, na tentativa de auxiliar os professores, a CP afirmou que utilizava os momentos do curso de formação sobre o EMAI para que possam discutir e buscar alternativas ao ensino e à aprendizagem das atividades propostas. Contudo, durante as conversas, as participantes afirmaram que o termo "curso" está sendo erroneamente empregado, pois o foco desses momentos, que eles chamaram de "grupo" / "encontros", eram as discussões, consideradas superficiais, pois estão ligadas a apenas algumas atividades, tornando o entendimento conceitual ainda limitado.

O que acontece na escola não é curso, não! Na verdade, nós tivemos as orientações com a nossa coordenadora uma vez por semana. Era um trabalho de entendimento da atividade. A cada encontro estudávamos uma atividade considerada difícil de cada ano. [Profa. Joana].

Acredito que esses encontros não foram, ou melhor, não são, parte de um 'curso', porque não há teoria que embasa [tais encontros], há apenas a revisão de algumas atividades do EMAI. Sinceramente, na maioria das vezes, utilizamos esses horários para correção de avaliações... [Profa. Eva].

Portanto, é possível concluir que não foram abordados nessas discussões: os conceitos matemáticos que cada atividade leva a compreender, o embasamento teórico do projeto e o objetivo de sua criação. É apenas um momento de estudo das atividades, caracterizado aqui como um processo que fragmenta o saber, visto que não considera as questões filosóficas e políticas que alicerçam a proposta do governo. Para Gregolin (2006), é importante perceber o sujeito da escrita como parte do texto, e suas ideias, pressupostos e ideologias devem estar latentes na materialidade do texto, 
na maneira de escrever e no que está sendo dito. A insuficiência da formação dos professores torna superficial o entendimento do projeto EMAI e, consequentemente, das imposições ideológicas que sustentam sua escrita.

É interessante notar que a professora Eva sente a necessidade de entender a "teoria que embasa" os encontros. Ela parece reconhecer que é importante o conhecimento teórico como fundamento da prática, mesmo não percebendo que há uma teoria que alicerça todo o material e está imbuída na fala da coordenadora que ministra os encontros e em todo o material didático, assim como a carga ideológica que ambos carregam e disseminam.

Essa insuficiência fica evidente também na sala de aula, que deveria ser o local onde se concretiza a vivência da teoria na prática, pois o professor se ambienta com as necessidades e os desafios para a construção do sentido do ato educativo na troca com os alunos e com os pares. Para Freire (2016), a sala de aula deveria ser o local em que professores e alunos tivessem a oportunidade de participar ativamente dos processos de ensino e aprendizagem e de se transformarem por meio de uma relação de troca e diálogo com o conhecimento. Entretanto, como buscar essa relação de troca se o conhecimento pode permanecer sincrético e desordenado do início ao fim do processo?

Seria preciso que, dentro de uma identidade docente autônoma, se concretizasse a educação crítica como centro do processo de ensino e de aprendizagem e a formação continuada fosse um movimento de busca e reflexão constantes acerca da própria prática e do próprio conhecimento. No excerto que segue, é possível observar o sentimento de esperança da professora quanto ao desenvolvimento profissional: "Eu acho que o trabalho com a Matemática tem muito a crescer ainda nas escolas do Estado, sinto uma carência muito grande de matemáticos, porque nós, pedagogos, temos uma formação muito precária..." [Profa. Eva].

A esperança de crescimento, representada na fala da professora Eva, sustenta a necessidade de apoio ao trabalho docente via uma formação continuada mais adequada e uma formação inicial melhor estruturada no sentido conceitual para o trabalho efetivo com a matemática. É por isso que as falas das educadoras foram fundamentadas na implantação do EMAI como uma oportunidade de ajudar o professor dos anos iniciais a superar as falhas e facilitar o trabalho com a matemática.

Se o professor teve uma má formação inicial ou alguma lacuna, o EMAl poderá dar a ele um ponto de partida, para ter noção de onde começar... [Profa. Joana].

As crianças têm muito mais dificuldade com a Matemática e, por isso, precisam de professores capazes de indicar caminhos, por isso, a necessidade de uma formação melhor. Há uma dificuldade grande em traduzir a teoria na prática... [Profa. Rita].

Os professores sentem a necessidade de formações que possibilitem sua valorização e participação efetiva no trabalho com a matemática, tanto no sentido da aquisição de conteúdos específicos quanto de metodologias que contribuam para o aprimoramento dos processos de ensino e aprendizagem, de modo a fazer avançar seus saberes docentes e a prática educativa, tendo mais segurança nos momentos de intervenção direta com os alunos, em um movimento ininterrupto de ensino, reflexão e retomada, mesmo para o trabalho com o material EMAI, pois as atividades exigem do professor um estudo sistemático e o domínio do conteúdo, como destaca a professora Eva: 
O material do EMAl é problemático para aquele professor que não quer estudar, que não quer ler, analisar. Aí, não vai ter avanço nenhum, pois esse professor vai direto para a atividade, vai resolver a atividade com o aluno e vai acabar caindo no livro didático, a mesma coisa.

Monteiro (2006), ao analisar a questão da formação de professores como uma necessidade real, reconhece que o professor é um intelectual que precisa ser ouvido no momento da formação continuada. Esta precisa levar em conta o educador e suas reais necessidades, como uma forma de superar os cursos de formação continuada que apresentam apenas fórmulas prontas de ensino consideradas neutras e verdadeiras, de modo que as atividades podem se tornar um fazer sem pensar, um executar sem refletir.

É por isso que os professores precisam ser os responsáveis pelas decisões e ações, em especial no momento da formação continuada, levando em conta suas vivências, tanto na graduação quanto na prática de sala de aula, para que o professor compreenda sua posição como um intelectual que reafirma a importância da compreensão dos conceitos em detrimento da acumulação de dados, como afirmam Pozo e Crespo (2009).

\section{A formação continuada precisa me ajudar a tomar caminho, ou seja, o que é que eu vou precisar fazer para essa turma e suas dificuldades. Se eu não tiver essa formação, eu não vou conseguir ter autonomia... [Profa. Rita].}

A compreensão do conteúdo e dos procedimentos, portanto, é uma condição necessária para a aprendizagem efetiva, tanto de professores quanto de alunos. Por meio da troca de saberes e experiências, esse processo de compreensão tornar-se-á possível, de modo que essas trocas precisam, necessariamente, ser acompanhadas de cursos de formação continuada que tragam ao professor os subsídios necessários à transformação da realidade educacional brasileira, em especial no que se refere à matemática.

Sempre busquei aprofundar meus conhecimentos nos livros, alguns cursos e orientações. A parceria com colegas é sempre valiosa, mas não tenho a menor segurança para trabalhar com alguns conteúdos... [Profa. Joana].

Minha formação inicial me ajudou, mas de modo muito superficial, pois tenho que estudar muito, já que esta disciplina é minha maior dificuldade, principalmente nos conteúdos como fração, número decimal, etc. [Profa. Rita].

Assim, entendemos que a formação continuada precisa ser um alicerce para a reflexão sobre a formação inicial e a própria prática educativa, a partir da relação estreita com o outro, tanto para a aprendizagem quanto para o estabelecimento de vínculos afetivos, do estudo sobre os conceitos referentes à disciplina estudada, bem como das metodologias que auxiliariam o professor no favorecimento da aprendizagem dos alunos.

Isso porque o processo de construção de uma identidade docente autônoma permeia inúmeros elementos que irão alicerçando todo o percurso de formação e, essencialmente, tais elementos precisam estar sustentados em uma teoria, uma linha filosófica de sua escolha, de seu domínio político e técnico, uma vez que essa é a essência da autonomia, ou seja, a práxis educativa alicerçada na teoria e na prática consciente e crítica de sua capacidade formadora e disseminadora de ideologias. Por isso, é preciso ter clareza de qual posicionamento filosófico adotará como professor. 
Pelos apontamentos feitos nas entrevistas, percebemos que o professor quer entender também tudo o que fora abordado acerca dos conceitos e procedimentos metodológicos e os condicionantes políticos e filosóficos que sustentam os programas do Governo. Entretanto, o tempo das discussões em grupo foi destinado ao entendimento das atividades, já que os professores apresentaram lacunas conceituais graves. Isso pode ser observado na fala a seguir:

Faz muita falta, também, um estudo dos aspectos políticos e filosóficos do material, pois, no dia a dia, sem ter a discussão, a reflexão de outros sobre o assunto, acabamos ficando no senso comum, pois a gente está tão preocupado com a aula que a gente não consegue refletir sobre o que está por trás de tudo isso, os conceitos políticos e filosóficos. [Profa. Eva].

Reconhecer essa necessidade já é um importante passo à reflexão, ao debate, à evolução na compreensão das teorias educacionais e, o mais importante, à compreensão dos condicionantes ideológicos que impedem o professor de refletir e transformar sua prática educativa e escolher sua linha filosófica e seus procedimentos práticos.

Ademais, ainda falta a formação necessária para que essa compreensão seja efetiva, pois o estudo, tão essencial para o professor, encontra barreiras na questão do tempo, do custo e do cansaço físico e mental. E os momentos de estudo oferecidos nas unidades escolares não proporcionam oportunidades de real reflexão sobre a questão da autonomia como parte fundamental da identidade docente.

O conhecimento sobre a amplitude do conceito de autonomia se revela na fala da professora Joana, ao afirmar que são as sequências didáticas do EMAI que expandem sua autonomia, relacionando-a à execução do trabalho imposto.

A sequência proposta para o trabalho do professor (conversa inicial, problematização e intervenção) expande a autonomia, pois cada sala é uma realidade e as possibilidades são infinitas. [Profa. Joana].

Concordamos que as possibilidades são infinitas, pois as salas de aula são diferentes e possuem realidades específicas. Mas, como ampliar as discussões se a sequência de intervenção já está determinada no material? Isso demonstra que muitos professores não reconhecem que essas sequências são limitadoras do trabalho reflexivo e não estimulam o desenvolvimento de uma autonomia real, a qual, como anteriormente enfatizado, é uma construção integral de muitos fatores, especialmente, do currículo, a partir do qual ele pode planejar, executar e refletir junto com seus alunos, não por meio de propostas prontas, mas pela elaboração coletiva.

A autonomia, portanto, torna-se, como definimos aqui, relativa, condicionada ao ato de executar um programa de ensino determinado. A responsabilidade fica condicionada à importância de cumprir atividades, em que a capacitação é apenas para a aplicação correta delas.

Tenho autonomia, sim, porque eu posso pegar o EMAl, estudar o EMAl com antecedência, pois não dá pra eu chegar na sala de aula, pegar o livro, bater o olho e decidir o que aplicar na hora. Agora eu posso adequar a minha atividade complementar. Ele é um norte a ser adequado para minha sala de aula. Eu não me sinto limitada por ele, tenho autonomia... [Profa. Joana].

Essa autonomia, a gente vai criando. Eu, por exemplo, busco minha autonomia, conhecendo o material e as práticas a cada dia, tentando superar a burocracia do sistema. [CP Maria].

Ambas disseram não se sentirem limitadas pelo material, mas a professora Rita teve um posicionamento diferente, ao afirmar que "Ele não me dá autonomia porque já 
veio pronto e tudo o que vem pronto me amarra. Se antes tínhamos o livro didático, hoje temos o EMAl e é a ele que eu tenho que obedecer. Nesse ponto, ele tira minha autonomia". [Profa. Rita].

Nessas falas, foi possível verificar a contradição existente entre o pensamento das professoras sobre a questão da autonomia frente ao projeto EMAI. Nesse sentido, a professora Rita demonstrou compreensão do termo ao enfatizar a "amarra" imposta pelo material e a necessidade de seguir com as complementações das atividades. Segundo Contreras (2002, p. 80), essa estipulação do currículo das escolas acaba reduzindo a participação da sociedade nos procedimentos burocratizados e "[...] forçando os professores ao papel de funcionário obediente e ao resto da sociedade ao de espectadores".

Desse modo, a compreensão da limitação da autonomia que ocorre pela imposição dos materiais didáticos passa a ser um alicerce necessário aos professores na luta por soluções para os problemas que envolvem o cenário educacional atual, sempre considerando as questões concernentes à formação docente, a construção da identidade docente autônoma, a relação com os pares e os alunos e à participação efetiva nas decisões escolares, discussões e transformações.

No que segue, traçaremos as considerações finais desta pesquisa, a qual tratou de um tema relevante ao cenário educacional na atualidade: a autonomia como possibilidade real na construção da identidade docente frente aos programas do governo.

\section{Considerações finais}

Para finalizar, à luz dos referenciais teóricos adotados, retomaremos as questões postas inicialmente, a saber: Como os professores entrevistados entendem sua autonomia docente na utilização desse material didático? Qual a contribuição desse uso no que concerne à construção de sua identidade docente? A fim de apontar elementos que apresentem avanços no que tange à questão da formação de professores e à construção da identidade docente autônoma.

A partir da análise das entrevistas, foi possível evidenciar que o uso do material EMAI dá ao professor maior segurança para o trabalho com a matemática em virtude das lacunas advindas de suas formações, inicial e continuada, tanto em relação ao suporte teórico quanto prático.

Ficou evidente que a formação inicial é um ponto falho para a maioria desses professores, principalmente no que se refere à matemática e, por isso, o currículo pronto desses programas, como é o caso do EMAI, fornece ao professor uma sensação de segurança, tanto em relação ao estudo, quanto à prática docente propriamente dita.

Entretanto, esses mesmos programas, apesar de transmitirem segurança, também são responsáveis pela falsa sensação de autonomia do professor, ou seja, eles se sentem autônomos pelo simples fato de conseguirem cumprir, na íntegra, todas as atividades do material e, ainda, buscar atividades que o complementem.

Entendemos que a autonomia, como defendida por Contreras (2002), vai muito além da atividade prática, da execução daquilo que está posto, pois está vinculada à intensa responsabilidade do professor em participar da elaboração, execução, análise e reformulação do currículo. Nesse sentido, a formação continuada será alicerce de 
reflexões no efetivo exercício de uma autonomia real, como parte imprescindível na construção de uma identidade docente autônoma e reflexiva.

Ao investigarmos sobre o trabalho com a matemática com as quatro professoras participantes, identificamos que, apesar de elas terem grande experiência profissional e estudado o material, demonstraram insegurança ao ensinar matemática e atribuíram essa culpa às suas deficitárias formações iniciais, em que não tiveram, nas grades curriculares dos cursos que fizeram, tempo suficiente para o estudo dos conceitos e das metodologias que facilitariam a prática pedagógica. Isso indica que os conceitos de matemática em cursos de formação inicial deveriam ser suficientemente tratados tanto do ponto de vista de conteúdos, como também de metodologias voltadas aos anos iniciais do Ensino Fundamental.

Nesse sentido, a pesquisa apontou indícios de que a implantação de programas do Governo e a precariedade de cursos de formação continuada que não valorizem as necessidades do professor acabam por limitar a prática pedagógica crítica e reflexiva, como evidenciamos na pesquisa com o material EMAI.

O uso do material didático como único condutor conceitual e procedimental das aulas é entendido aqui como um dos limitadores da autonomia docente pela imposição de um planejamento pronto a ser seguido e executado sem questionamento, mantendo o professor preso ao cumprimento do currículo do modo como está determinado. Ademais, reconhecemos a inquietação, a percepção das imposições do sistema político-educacional que condiciona o trabalho e a tomada de consciência da existência de uma autonomia relativa como possibilidades da entrada em um processo de produção de resistências.

É perceptível que, na prática do professor que atua com um currículo pronto, há o risco de haver uma autonomia apenas relativa, condicionada pelas imposições ideológicas dos programas do Governo que dão ao professor uma falsa sensação de autonomia. Vale ainda ressaltar que nem sempre os professores conseguem perceber a necessidade de entender as especificidades de uma identidade docente autônoma para uma atuação crítica, tanto para a mudança no âmbito escolar como fora dele, pensando na sociedade de um modo geral e no papel relevante que a educação tem na formação de cidadãos conscientes e críticos.

É necessário que os professores se percebam como intelectuais, que precisam buscar, por meio do seu estudo e trabalho, a autonomia real como estrutura fundante da identidade docente. Mas, para isso, é preciso que a formação continuada traga os subsídios que a formação inicial não proporcionou.

Portanto, a ênfase está na formação docente de qualidade para a tomada de consciência, fundamentada na reflexão sobre o pensamento crítico, político e filosófico, além do domínio dos conteúdos conceituais e procedimentais. São ferramentas essenciais para entender a realidade imediata a qual está inserido como decorrente de um processo histórico que essencialmente está sustentado na exploração do trabalho e na dominação ideológica inserida no cerne da formação do indivíduo, trazendo as reflexões para a atuação política consciente em sala de aula, na luta contra as imposições sofridas cotidianamente dentro e fora do sistema escolar que burocratizam o trabalho do professor (PIRES, 1997).

A atuação consciente e crítica tem sua formação sustentada na potência crítica, na competência técnica e no compromisso político com a educação pública 
de qualidade, que tem em sua essência a transformação da sociedade por meio do trabalho coletivo, de uma coletividade politizada e sistematicamente consciente de sua força transformadora como classe organizada (LUKÁCS, 2003). Por isso, enfatizamos, no decorrer do texto, a importância da educação escolar como parte de um processo essencial na luta pelo acesso de todos aos bens culturais e materiais.

A pesquisa revelou também que as professoras participantes estavam submetidas a uma dependência tanto no que refere a aspectos conceituais quanto no que diz respeito a aspectos práticos, pois as atividades e as diretrizes para a condução da aula já estão determinadas. Cabe ainda destacar que o caminho proposto para atingir as expectativas de aprendizagem, por si só, não oferece ao professor a oportunidade de planejar suas aulas, seus encaminhamentos e traçar suas próprias análises.

Identificamos que o aspecto positivo das entrevistas é a mobilização para a reflexão, dando aos professores a oportunidade de pensar sobre os caminhos que estão seguindo, reconhecer a precariedade de seu conhecimento científico e lutar por uma formação continuada de qualidade que supra suas necessidades, não somente para o crescimento pessoal, mas também para auxiliar os parceiros e, principalmente, os alunos.

O grande problema identificado não é a aplicação das atividades, mas o uso do material de forma automática, sem a compreensão dos programas e a alienação em relação ao entendimento do suporte político e filosófico que sustenta seu uso.

A partir dessas reflexões, entendemos que há necessidade de que os cursos de formação favoreçam a participação docente, a atualização e a ampliação do conhecimento científico-educacional, o uso de estratégias de ensino e aprendizagem capazes de contribuir com as atividades em sala, sendo o professor, por meio desse trabalho, um multiplicador (SELLES, 2002 apud REDLING, 2011, p. 106).

Todos esses aspectos constituem elementos essenciais para que o professor seja autônomo, considerado aqui como aquele que atua criticamente e usa um discurso consciente, tanto no aspecto conceitual quanto pedagógico e, em sua práxis pedagógica, atue pela transformação social e não pelo conformismo.

\section{Referências}

BOGDAN, R. C.; BIKLEN, S. K. Investigação qualitativa em educação: uma introdução à teoria e aos métodos. Porto: Porto Editora, 1994.

CONTRERAS, J. A autonomia de professores. São Paulo: Cortez, 2002.

CUNHA, M. I. Docência na universidade, cultura e avaliação institucional: saberes silenciados em questão. Revista Brasileira de Educação, Rio de Janeiro, v. 11, n. 32, p. 258-371, maio/ago. 2006. DOI: https://doi.org/10.1590/S1413-24782006000200005.

FREIRE, P. Pedagogia da autonomia: saberes necessários à prática educativa. São Paulo: Paz e Terra, 1996.

FREIRE, P. Pedagogia do oprimido. 60. ed. Rio de Janeiro: Paz e Terra, 2016.

GRAMSCI, A. Os intelectuais e a organização da cultura. 4. ed. Rio de Janeiro: Civilização Brasileira, 1982.

GRAMSCI, A. Maquiavel, a política e o estado moderno. Rio de Janeiro: Civilização Brasileira, 1968. 
GREGOLIN, M. R. Foucault e Pêcheux na análise do discurso: diálogos e duelos. 2. ed. São Carlos: Claraluz, 2006.

LUDKE, M.; ANDRÉ, M. Pesquisa em educação: abordagens qualitativas. São Paulo: EPU, 1986.

LUKÁCS, G. História e consciência de classe: estudos sobre a dialética marxista. São Paulo: Martins Fontes, 2003.

MARTINS, L. M. O legado do século XX para a formação de professores. In: MARTINS, L. M.; DUARTE, N. (org.). Formação de professores: limites contemporâneos e alternativas necessárias. São Paulo: Cultura Acadêmica, 2010. p. 13-31.

MONTEIRO, M. A. A. Um estudo da autonomia docente no contexto do ensino de ciências nas séries iniciais do ensino fundamental. 2006. 305 f. Tese (Doutorado em Educação para a Ciência) Universidade Estadual Paulista, Faculdade de Ciências, Bauru, 2006.

PIRES, M. F. C. O materialismo histórico-dialético e a educação. Interface, Botucatu, v. 1, n. 1, p. 83-94, 1997. DOI: https://doi.org/10.1590/S1414-32831997000200006.

POZO, J. I.; CRESPO, M. A. G. A aprendizagem e o ensino de ciências: do conhecimento cotidiano ao conhecimento científico. 5. ed. Porto Alegre: Artmed, 2009.

REDLING, J. P. A metodologia de resolução de problemas: concepções e práticas pedagógicas de professores de matemática do ensino fundamental. 2011. 166 f. Dissertação (Mestrado em Educação) - Universidade Estadual Paulista, Faculdade de Ciências, Bauru, 2011. Disponível em: http://hdl.handle.net/11449/90928. Acesso em: 31 maio 2021.

SÃO PAULO (Estado). Secretaria da Educação. EMAl: educação matemática nos anos iniciais do ensino fundamental: quarto ano: organização dos trabalhos em sala de aula: material do professor. São Paulo: SE, 2013.

SAVIANI, D. Educação: do senso comum à consciência filosófica. 14. ed. Campinas: Autores Associados, 2002.

SAVIANI, D. Escola e democracia. 37. ed. São Paulo: Autores Associados, 2005.

SAVIANI, D. A pedagogia no Brasil. Campinas: Autores Associados, 2008.

SAVIANI, D. Pedagogia histórico-crítica: primeiras aproximações. 8. ed. Campinas: Autores Associados, 2003.

SILVA, E. S. Desenvolvimento curricular de matemática nos anos iniciais na perspectiva do professor e do coordenador: um estudo do Projeto EMAI de São Paulo. 2015. 150 f. Dissertação (Mestrado Profissional em Educação) - Centro de Educação e Ciências Humanas, Universidade Federal de São Carlos, São Carlos, 2015.

\section{ERRATA}

Na página 1, onde se lia:

"Augusta Teresa Teresa Barbosa Barbosa Severino"

\section{Leia-se:}

"Augusta Teresa Barbosa Severino"

Ciência \& Educação, Bauru, v. 27, e21026, p. 18, 2021. 